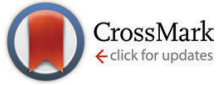

Cite this: Phys. Chem. Chem. Phys., 2014, 16, 26638

Received 15th October 2014, Accepted 27th October 2014

DOI: $10.1039 / c 4 c p 04693 e$

www.rsc.org/pccp

\title{
Optimised photocatalytic hydrogen production using core-shell AuPd promoters with controlled shell thickness $\dagger$
}

\author{
Wilm Jones, ${ }^{a b}$ Ren Su, ${ }^{\star c}$ Peter P. Wells, ${ }^{\text {ad }}$ Yanbin Shen, ${ }^{\text {ce }}$ Nikolaos Dimitratos, ${ }^{a b}$ \\ Michael Bowker, ${ }^{\text {ab }}$ David Morgan, ${ }^{b}$ Bo B. Iversen, ${ }^{c e}$ Arunabhiram Chutia, ${ }^{\text {ad }}$ \\ Flemming Besenbacher ${ }^{c}$ and Graham Hutchings*ab
}

\begin{abstract}
The development of efficient photocatalytic routines for producing hydrogen is of great importance as society moves away from energy sources derived from fossil fuels. Recent studies have identified that the addition of metal nanoparticles to $\mathrm{TiO}_{2}$ greatly enhances the photocatalytic performance of these materials towards the reforming of alcohols for hydrogen production. The core-shell structured $\mathrm{Au}-\mathrm{Pd}$ bimetallic nanoparticle supported on $\mathrm{TiO}_{2}$ has being of interest as it exhibited extremely high quantum efficiencies for hydrogen production. However, the effect of shell composition and thickness on photocatalytic performance remains unclear. Here we report the synthesis of core-shell structured AuPd NPs with the controlled deposition of one and two monolayers (ML) equivalent of Pd onto Au NPs by colloidal and photodeposition methods. We have determined the shell composition and thickness of the nanoparticles by a combination of X-ray absorption fine structure and X-ray photoelectron spectroscopy. Photocatalytic ethanol reforming showed that the core-shell structured Au-Pd promoters supported on $\mathrm{TiO}_{2}$ exhibit enhanced activity compared to that of monometallic $\mathrm{Au}$ and $\mathrm{Pd}$ as promoters, whilst the core-shell Au-Pd promoters containing one ML equivalent Pd provide the optimum reactivity.
\end{abstract}

\section{Introduction}

Photocatalytic hydrogen $\left(\mathrm{H}_{2}\right)$ production is an attractive method of converting solar energy into chemical energy, ${ }^{1,2}$ with $\mathrm{H}_{2}$ showing great promise as a future fuel. Indeed, the move towards a $\mathrm{H}_{2}$ economy is driven by the impact of $\mathrm{CO}_{2}$ emissions and ever diminishing reserves of fossil fuels. Currently, more than $90 \%$ of $\mathrm{H}_{2}$ is produced via steam reforming of hydrocarbons, an energy intensive process which requires high temperature $\left(700-1100{ }^{\circ} \mathrm{C}\right) .^{3}$ However, as this process is still fundamentally driven by the consumption of fossil fuels, there has been a desire to harness the energy from the sun to

\footnotetext{
${ }^{a}$ The UK Catalysis Hub, Research Complex at Harwell, Rutherford Appleton Laboratory, Oxfordshire, OX11 OFA, UK

${ }^{b}$ Cardiff Catalysis Institute, School of Chemistry, Cardiff University, Cardiff, CF10 3AT, UK. E-mail: Hutch@cardiff.ac.uk

${ }^{c}$ Interdisciplinary Nanoscience Center (iNANO) and Department of Physics and Astronomy, Aarhus University, Gustav Wieds Vej 14, DK-8000 Aarhus C, Denmark. E-mail: rensu@inano.au.dk

${ }^{d}$ University College London, Kathleen Lonsdale Materials, Department of Chemistry, Gordon Street, London, WC1H OAJ, UK

${ }^{e}$ Department of Chemistry, Aarhus University, Langelandsgade 140, DK-8000 Aarhus C, Denmark

$\dagger$ Electronic supplementary information (ESI) available. See DOI: 10.1039/ c4cp04693e
}

produce $\mathrm{H}_{2}$. The photocatalytic reforming of alcohols (i.e., methanol, ethanol, and glycerol) using semiconductor based materials offers an alternative route for the production of $\mathrm{H}_{2}$ at ambient conditions. ${ }^{4}$

Titanium dioxide $\left(\mathrm{TiO}_{2}\right)$ has received significant attention as an efficient semiconductor for photocatalysis applications, ${ }^{4-9}$ which is largely as a consequence of its relative low recombination rate, non-toxicity, stability, and abundance. ${ }^{10}$ Photocatalytic $\mathrm{H}_{2}$ production by $\mathrm{TiO}_{2}$ based materials relies on the generation of electron-hole $\left(\mathrm{e}^{-}\right.$and $\left.\mathrm{h}^{+}\right)$pairs via absorption of photons with energy equal to or greater than the band gap $(3.2 \mathrm{eV}$ for anatase). ${ }^{11}$ The pairs either recombine or react with surface adsorbed species; therefore an effective photocatalyst should be able to inhibit recombination whilst utilising the electronhole pairs to perform redox reactions efficiently. However, previous studies have shown that pristine $\mathrm{TiO}_{2}$ based materials are poor photocatalyst materials for reforming reactions, ${ }^{12}$ as the charge transfer from $\mathrm{TiO}_{2}$ to surface adsorbed alcohols is significant slower than that of the recombination kinetics.

The addition of precious metal (i.e., $\mathrm{Pt}, \mathrm{Pd}, \mathrm{Au}$, and $\mathrm{Ag}$ ) nanoparticles (NPs) on the surface of $\mathrm{TiO}_{2}$ can greatly enhance the $\mathrm{H}_{2}$ production efficiency. ${ }^{13-16}$ The promotional effect of the metal NPs can be understood in terms of the energy levels of the semiconductor-metal system, where the photo-excited 
conduction band (CB) electrons on the surface of $\mathrm{TiO}_{2}$ can be rapidly transferred and trapped at the surface of NPs. ${ }^{17}$ This prolongs the lifetime of the trapped electrons thus improving the photoreactivity. ${ }^{18,19}$ To further tune the charge separation efficiency, modification of $\mathrm{TiO}_{2}$ with bimetallic NPs has also been studied (i.e., AuPt, AgPt, and AuPd). ${ }^{2,20,21}$ Recent work by $\mathrm{Su}$ et al. on AuPd NPs as promoters has shown the structure of the NPs to be important to the activity of the photocatalyst. Their study highlighted $\mathrm{Pd}_{\text {shell }}-\mathrm{Au}_{\text {core }}$ structured NPs demonstrated the highest photoreactivity with excellent reusability in comparison to other possible structures. ${ }^{18,22}$ This increase in activity was attributed to the structured NPs increased ability to inhibit the reverse transfer of trapped electrons back to $\mathrm{TiO}_{2}$, whilst simultaneously providing a fast reduction rate of the surface adsorbed reagents. The enhanced photocatalytic performance caused by the interaction between AuPd alloy and $\mathrm{TiO}_{2}$ was also reported by Mizukoshi et al. ${ }^{23}$ Moreover, recent research on photocatalytic benzene oxidation further suggested that the interplay of AuPd alloy and $\mathrm{TiO}_{2}$ led to a significantly improvement of selective conversion of phenol. ${ }^{24}$ These investigations also indicate the thickness and composition of the shell layer may influence the electronic properties of the promoters. Chemical vapour impregnation (CVI) approach have been also reported as a promising technique for the decoration of semiconductor photocatalyst with surface clean metal promoter NPs. ${ }^{22}$ However, synthesis of metal NPs with controlled shell thickness and composition has been seldom performed due to the challenges in preparation. As a consequence, although the physical properties of the shell layer of the promoter was considered to be an essential parameter, how it influence the photocatalytic performance was still unclear. Moreover, the properties of the shell layer have been normally determined by microscopic methods, which left the overall features of the shell layer remaining uncertain.

This study reports the synthesis of core-shell structured $\mathrm{Au}-\mathrm{Pd}$ metal NPs with controlled shell thickness using both photodeposition and sequential reduction routes. Moreover, by depositing only thin layers of Pd it allows bulk characterisation techniques, such as X-ray absorption fine structure (XAFS), to provide some degree of surface sensitive information. ${ }^{25}$ Indeed, the thin layers of Pd deposited here allow us to ascertain the coreshell nature of these materials in more detail. Herein, this study we demonstrate how a change in the microstructure of the metal promoter influences the photocatalytic $\mathrm{H}_{2}$ evolution performance.

\section{Experimental}

\section{Catalyst preparation}

For the synthesis of core-shell structured metal NPs supported on $\mathrm{TiO}_{2}$, we first prepared $1 \mathrm{wt} \%$ of $\mathrm{Au}$ supported on $\mathrm{TiO}_{2}$ $\left(\mathrm{Au} / \mathrm{TiO}_{2}\right)$ by standard sol immobilisation. ${ }^{26}$ Then thin layers of Pd were deposited on $\mathrm{Au}$ using either by photodeposition or sequential reduction method, as demonstrated in below:

Photodeposition method (PD). The as-prepared $\mathrm{Au} / \mathrm{TiO}_{2}$ photocatalyst was placed in a Pyrex round bottom flask with
$250 \mathrm{~mL}$ of Milli Q water and sonicated for 1 hour to obtain a homogeneous dispersion of the catalyst. To which a solution of $\mathrm{K}_{2} \mathrm{PdCl}_{4}$ corresponding to a thickness of either one or two ML of Pd was added. Reduction of the Pd precursor was performed by photo irradiation using a Lot-Oriel solar simulator (LSO104) containing a $150 \mathrm{~W}$ Xe arc lamp under continuous stirring. After two hours the mixture was filtered and dried at $120{ }^{\circ} \mathrm{C}$ for 8 hours to produce the final photocatalysts. The samples were labelled as $1 \mathrm{ML}(\mathrm{PD})$ and $2 \mathrm{ML}(\mathrm{PD})$, respectively.

Sequential reduction method (SR). The as-prepared $\mathrm{Au} / \mathrm{TiO}_{2}$ photocatalyst was added into $800 \mathrm{~mL}$ of Milli Q water and sonicated for 1 hour to disperse the catalyst. To which a solution of $\mathrm{K}_{2} \mathrm{PdCl}_{4}$ corresponding to a thickness of either one or two ML of Pd was added. Reduction of the Pd precursor was performed by addition of excessive $\mathrm{NaBH}_{4}$. After 30 minutes of reduction, the mixture was filtered and dried at $120{ }^{\circ} \mathrm{C}$ for 8 hours to produce the final photocatalysts. The samples were labelled as $1 \mathrm{ML}(\mathrm{SR})$ and $2 \mathrm{ML}(\mathrm{SR})$, respectively.

\section{Catalyst characterisation}

Transmission electron microscopy (TEM). Samples were prepared for TEM characterisation by dispersing the catalyst powder in high purity ethanol, followed by sonication for 10 minutes. A drop of this suspension was then evaporated on a holey carbon film supported by a 300 mesh copper TEM grid. Samples were then subjected to bright field diffraction contrast imaging in order to determine particle size distribution. The TEM instrument used for this analysis was a JOEL-2100 with a $\mathrm{LaB}_{6}$ filament operated at $200 \mathrm{kV}$.

Calculation of dispersion. Transmission electron microscopy (TEM) was used to construct a particle size histogram for the $\mathrm{Au} / \mathrm{TiO}_{2}(1 \mathrm{wt} \%)$ catalyst produced by the sol immobilisation method based on measurement of 335 particles. Surface average diameter $\left(S_{\mathrm{ad}}\right)$ and dispersion $(D)$ was then calculated from the particle size histogram using the following equations: ${ }^{27}$

$$
\begin{gathered}
S_{\mathrm{ad}}=1 /\left(\sum n d^{3} / \sum n d^{2}\right) \\
D=1 / S_{\mathrm{ad}}=N_{\mathrm{S}} / N_{\mathrm{T}}
\end{gathered}
$$

where $n$ is the number of particles with diameter $d, N_{\mathrm{S}}$ and $N_{\mathrm{T}}$ are the number of surface atoms and number of total atoms of the $\mathrm{Au}$ NPs in $\mathrm{Au} / \mathrm{TiO}_{2}$. Dispersion for the $\mathrm{Au} / \mathrm{TiO}_{2}$ was calculated to be 0.327 assuming the particles are spherical. For $1 \mathrm{~g}$ of $\mathrm{Au} / \mathrm{TiO}_{2}$ the number of surface atoms was then calculated to be $1.66 \times 10^{-5}$ moles.

X-ray photoelectron spectroscopy (XPS). X-ray photoelectron spectra were recorded on a Kratos Axis Ultra DLD spectrometer employing a monochromatic $\mathrm{Al} \mathrm{K}_{\alpha} \mathrm{X}$-ray source $(75-150 \mathrm{~W})$ and analyser pass energies of $160 \mathrm{eV}$ (for survey scans) or $40 \mathrm{eV}$ (for detailed scans). Samples were mounted using double-sided adhesive tape and binding energies were referenced to the $\mathrm{C} 1 \mathrm{~s}$ binding energy of adventitious carbon contamination, which was taken to be $284.7 \mathrm{eV}$.

X-ray absorption fine structure (XAFS). Pd k-edge and $\mathrm{Au}$ L3-edge XAFS studies were carried out on the B18 beamline at 
the Diamond Light Source, Didcot, UK. Measurements were performed using a QEXAFS set-up with a fast-scanning $\mathrm{Si}(311)$ or (111) double crystal monochromator for Pd and Au measurements, respectively. All Pd samples were measured in transmission mode using ion chamber detectors and were diluted with cellulose and pressed into pellets to optimise the effective edgestep of the XAFS data. All transmission XAFS spectra were acquired concurrently with a Pd foil placed between $I_{\mathrm{t}}$ and $I_{\text {ref }}$. The time resolution of the Pd spectra reported herein was 5 min per spectrum $\left(k_{\max }=14\right)$, on average three scans were acquired to improve the signal to noise level of the data. $\mathrm{Au} \mathrm{L}_{3}$ edge measurements were carried out in fluorescence mode, using a 9 element solid-state Ge detector as the $\mathrm{TiO}_{2}$ support was too absorbing to allow satisfactory acquisition in transmission. Au $\mathrm{L}_{3}$ edge fluorescence spectra were recorded with an acquisition time of $40 \mathrm{~min}$ per spectrum $\left(k_{\max }=14\right)$. XAFS data processing and Extended X-ray Absorption Fine Structure (EXAFS) analysis were performed using IFEFFIT $^{28}$ with the Horae package ${ }^{29}$ (Athena and Artemis). The amplitude reduction factor, $S_{0}{ }^{2}$, was derived from EXAFS data analysis of known reference compounds (Pd foil and $\mathrm{Au}$ foil) and used as a fixed input parameter. The EXAFS data was fitted in $R$ space with a typical fit range of $1<R<3.5 \AA$.

\section{Photocatalytic performance evaluation}

Photocatalytic evolution of $\mathrm{H}_{2}$ was carried out in a leak-tight reactor and products were analysed using a quadrupole mass analyser (MS, Hiden HPR-20). For all measurements, $25 \mathrm{mg}$ of the photocatalyst was dispersed into $18.75 \mathrm{~mL}$ of DI water in the reactor and subsequently UV irradiated using a UV-A LED light (WL: 365 nm, FWHM: $10 \mathrm{~nm}$, Tritan ${ }^{\mathrm{TM}} 365$, Spectroline) for $2.5 \mathrm{~h}$ to remove the protecting ligands. $6.25 \mathrm{~mL}$ of absolute ethanol (99\%) was then added in and the suspension was kept in the dark for $30 \mathrm{~min}$ to establish adsorption equilibrium prior to experiment. The reactor was then carefully evacuated for $30 \mathrm{~min}$ using a bypass rotary pump that was attached to the reactor. The dissolved $\mathrm{O}_{2}$ in the solution was calculated to be $\sim 5 \mu \mathrm{M}$ after evacuation for all tests. A two-hour irradiation was employed for the $\mathrm{H}_{2}$ evolution process under continuous stirring and the partial pressures of $m / z^{-}=2\left(\mathrm{H}_{2}\right), 18\left(\mathrm{H}_{2} \mathrm{O}\right), 28\left(\mathrm{~N}_{2}\right), 32\left(\mathrm{O}_{2}\right)$, and $44\left(\mathrm{CO}_{2}\right)$ were monitored. The light source was a UV LED (365 nm, Optimax 365) with a photon flux of $4 \times 10^{17}$ photons s $^{-1}$ for all $\mathrm{H}_{2}$ evolution experiments. Note that all incidents UV light can be sufficiently absorbed by the photocatalyst suspension (see assessment in ESI $\dagger$ ). All samples were characterised by similar optical properties, as shown in diffuse reflectance spectra (see Fig. S2 in ESI $\dagger$ ). Details of the photo-reactivity measurement and related calculations have been reported elsewhere. ${ }^{30}$ The produced $\mathrm{H}_{2}\left[n\left(\mathrm{H}_{2}\right)_{\text {gas }}\right]$ and the apparent quantum efficiency (AQE) can be therefore derived using the following equations: ${ }^{18}$

$$
\begin{gathered}
n\left(\mathrm{H}_{2}\right)_{\text {gas }}=p\left(\mathrm{H}_{2}\right)_{\text {rea }} \times V_{\text {rea }} / R T \\
p\left(\mathrm{H}_{2}\right)_{\text {rea }}=\operatorname{RSF}\left(\mathrm{H}_{2}\right) \times p\left(\mathrm{H}_{2}\right)_{\text {det }} \times p(\text { Air })_{\text {rea }} / p(\text { Air })_{\text {det }} \\
\mathrm{AQE}=2 n\left(\mathrm{H}_{2}\right)_{\text {gas }} / n(\text { photons }) \times 100 \%
\end{gathered}
$$

where, $p\left(\mathrm{H}_{2}\right)_{\text {rea }}$ is the partial pressure of $\mathrm{H}_{2}$ in the reaction chamber; $p\left(\mathrm{H}_{2}\right)_{\mathrm{det}}$ is the partial pressure of $\mathrm{H}_{2}$ detected by the
MS; $p$ (Air) $)_{\text {rea }}$ is the pressure of air in the reactor before evacuation $(100 \mathrm{kPa}) ; p$ (Air) $)_{\text {det }}$ is the pressure of air before evacuation detected by the MS; $V_{\text {rea }}$ is the gas-phase volume of the reactor $(190 \mathrm{~mL}) ; \mathrm{RSF}\left(\mathrm{H}_{2}\right)$ is the relative sensitivity factor of $\mathrm{H}_{2}(0.284)$.

$n$ (photons) is the number of incident photons within two hours, which is estimated to be $4.78 \mathrm{mmol}$ by using the photon

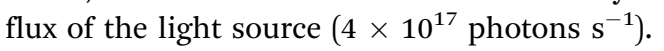

\section{Results and discussion}

\section{Structure characterisation}

TEM characterisation was performed on all materials to determine the metal particle size distribution. Representative TEM images and the derived histograms are shown in Fig. 1, and the calculated average particle sizes along with standard deviations are shown in Table 1. It is clear from the TEM images that all metal NPs were deposited on the $\mathrm{TiO}_{2}$ homogeneously, and there is no significant difference in particle size within all samples. The values of the standard deviation are roughly one third of the average particle size. As such, any particle size increase as a result of the Pd
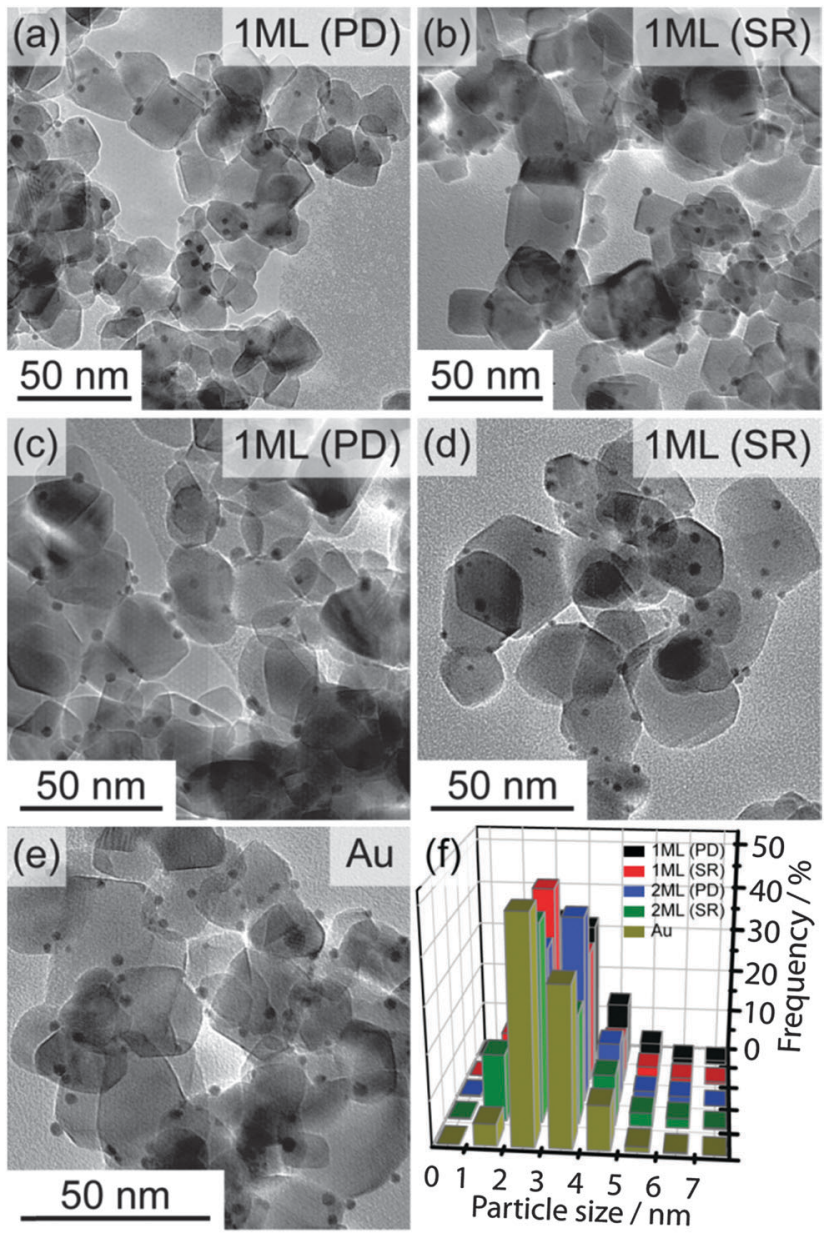

Fig. 1 Representative TEM images of (a) $1 \mathrm{ML}$ (PD), (b) $1 \mathrm{ML}$ (SR), (c) $2 \mathrm{ML}$ (PD), (d) $2 \mathrm{ML}$ (SR), and (e) Au nanoparticles supported on $\mathrm{TiO}_{2}$, respectively. The metal loading was $1 \mathrm{wt} \%$ for all samples (f) particle size distributions derived from corresponding TEM images. 
Table 1 Average particle size and standard deviation of the metal NPs calculated from more than 300 particles from multiple sites of all catalysts

\begin{tabular}{lll}
\hline Catalyst & Average particle size $(\mathrm{nm})$ & Standard deviation $(\mathrm{nm})$ \\
\hline $\mathrm{Au} / \mathrm{TiO}_{2}$ & 3.0 & 1.2 \\
$\mathrm{Pd} / \mathrm{TiO}_{2}$ & 3.2 & 1.0 \\
$1 \mathrm{ML}(\mathrm{SR})$ & 3.1 & 1.0 \\
$2 \mathrm{ML}(\mathrm{SR})$ & 2.8 & 1.0 \\
$1 \mathrm{ML}(\mathrm{PD})$ & 3.2 & 1.1 \\
$2 \mathrm{ML}(\mathrm{PD})$ & 3.3 & 1.1
\end{tabular}

modification is not observable. As the particle size has remained roughly constant, it is thought possible to rule out two potential scenarios, (i) Pd was deposited in small particles away from the Au only and (ii) Pd was deposited in large particles away from the Au only. In both cases the average particle size would be shifted to either smaller or larger values. This can be seen more clearly from TEM images and the particle size distribution histograms (Fig. 1). In fact, the Pd deposition is thought to proceed through a seed growth mechanism on the surface of the Au NPs in both preparation approaches. During the photo excitation of $\mathrm{Au} / \mathrm{TiO}_{2}$ it has been established that electrons will migrate to the metal surface, ${ }^{19}$ therefore the reduction and deposition of Pd should be predominately onto the surface of the $\mathrm{Au}$.

It is also possible that the Pd has been deposited separately on the surface of $\mathrm{TiO}_{2}$ with a particle size similar to that of initial $\mathrm{Au}$ NPs, which would mask their detection from this analysis. To support our claim that Pd has predominately deposited on $\mathrm{Au}, \mathrm{XPS}$ analysis was performed for all samples, as shown in Fig. 2(a)-(d) and summarised in Table 2 (O 1s spectra were shown in Fig. S4 in ESI $\dagger$ ). The survey scans (Fig. 2a) suggest all samples are mainly $\mathrm{TiO}_{2}$ with surface adventitious carbon and minor amount of metals (Au and Pd). Ti 2p spectra clearly show that neither deposition methods alter the oxidation states of Ti, which remained to be $\mathrm{Ti}^{4+}$ in all cases. Meanwhile, both Pd $3 \mathrm{~d}$ and Au $4 \mathrm{f}$ spectra indicate Pd and Au to be in their metallic form (Fig. 2c, d and Table 2). ${ }^{31,32}$ It is worth noting that when Pd NPs were deposited on $\mathrm{TiO}_{2}$ by conventional impregnation methods without the presence of capping ligands (i.e., PVA), the dominant species was PdO. ${ }^{33}$ Similar result was observed for the chemical vapour impregnated Pd NPs supported on $\mathrm{TiO}_{2}$ in our recent work, where the molar ratio of $\mathrm{Pd}^{0}: \mathrm{Pd}^{2+}$ was $\sim 1: 1 .^{22}$ This is not the case for the sol immobilisation method prepared $\mathrm{Pd} / \mathrm{TiO}_{2}$, as the NPs are encapsulated by the stabiliser. ${ }^{34}$ Interestingly, the deposition of metallic Pd in this study was performed in the absence of any stabiliser, which could be beneficial to photocatalysis applications due to the relative clean surface for interfacial charge transfer.

The oxidation state of Pd, determined by XPS, confirmed that only metallic Pd was found in all samples, indicating an interaction between $\mathrm{Au}$ and Pd that prevents the oxidation of $\mathrm{Pd}$. Surface atomic ratios of $\mathrm{Pd} / \mathrm{Au}$ were also calculated from the XPS spectra to give information on the structure on the NPs (Table 2). As expected increasing the thickness of the shell layer results in an increase of the $\mathrm{Pd} / \mathrm{Au}$ atomic ratio. Moreover, the surface atom ratio shows that the dominant component at the surface is $\mathrm{Au}$ in all cases. This suggests that the Pd may not be
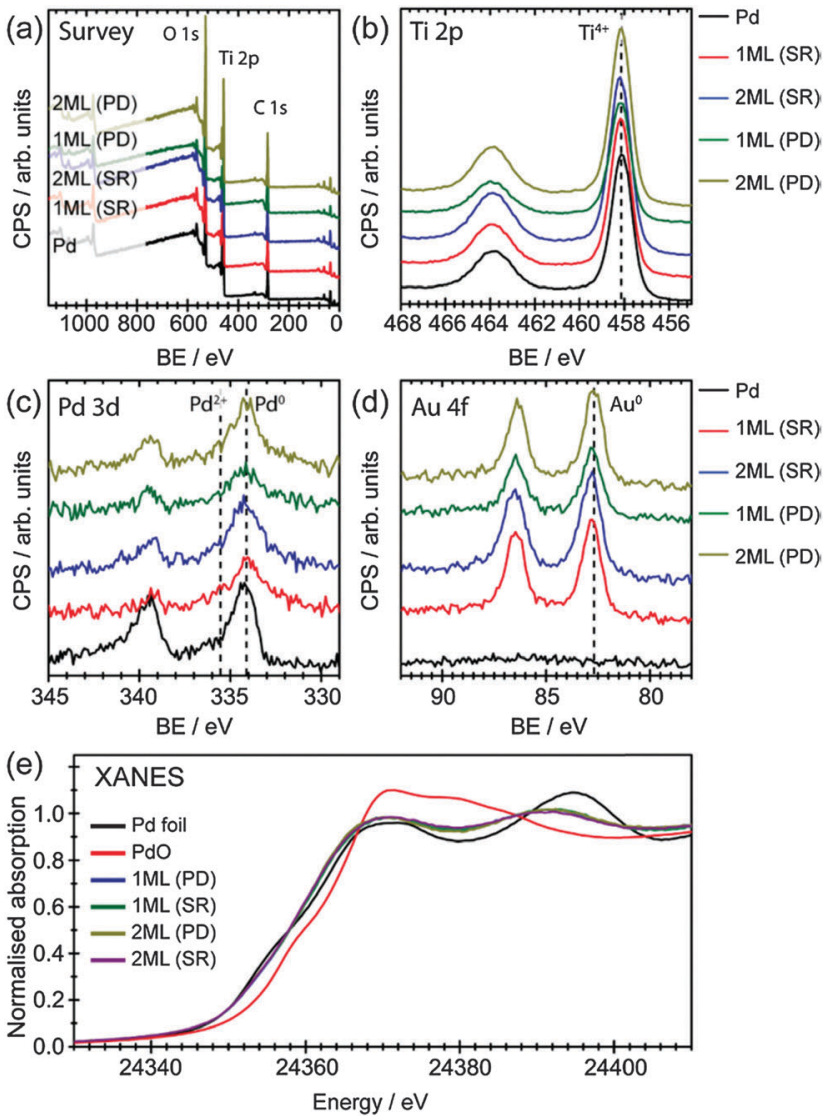

Fig. 2 (a) XPS survey spectra of the as-prepared metal NPs supported on $\mathrm{TiO}_{2}$. (b)-(d) High resolution XPS spectra of $\mathrm{Ti} 2 \mathrm{p}, \mathrm{Pd} 3 \mathrm{~d}$, and $\mathrm{Au} 4 \mathrm{f}$, respectively. (e) XANES spectra of Pd foil, PdO, $1 \mathrm{ML}$ (PD), $1 \mathrm{ML}$ (SR), $2 \mathrm{ML}$ (PD) and $2 \mathrm{ML}(\mathrm{SR})$.

Table 2 Summary of $P d 3 d$ and $A u 4 f$ binding energies and the derived $\mathrm{Pd} / \mathrm{Au}$ ratios from XPS analysis for $\mathrm{Au} / \mathrm{TiO}_{2}$ with 1 and $2 \mathrm{ML}$ of shell prepared by SR method and PD method, respectively

\begin{tabular}{|c|c|c|c|}
\hline Catalyst & Peak name & $\mathrm{BE}(\mathrm{eV})$ & $\mathrm{Pd} / \mathrm{Au}$ ratio \\
\hline \multirow[t]{2}{*}{$1 \mathrm{ML}$ (SR) } & Pd 3d & 334.1 & \multirow[t]{2}{*}{0.38} \\
\hline & $\mathrm{Au} 4 \mathrm{f}$ & 82.8 & \\
\hline \multirow[t]{2}{*}{$2 \mathrm{ML}$ (SR) } & Pd 3d & 334.2 & \multirow[t]{2}{*}{0.92} \\
\hline & $\mathrm{Au} 4 \mathrm{f}$ & 82.7 & \\
\hline \multirow[t]{2}{*}{$1 \mathrm{ML}$ (PD) } & Pd 3d & 334.2 & \multirow[t]{2}{*}{0.42} \\
\hline & $\mathrm{Au} 4 \mathrm{f}$ & 82.8 & \\
\hline \multirow[t]{2}{*}{$2 \mathrm{ML}(\mathrm{PD})$} & Pd 3d & 334.3 & \multirow[t]{2}{*}{0.63} \\
\hline & $\mathrm{Au} 4 \mathrm{f}$ & 82.7 & \\
\hline
\end{tabular}

present at the surface as a segregated overlayer, with the EXAFS analysis providing more detail on this.

X-ray absorption near edge structure (XANES) analysis have also been used to understand the oxidation states of these materials, as shown in Fig. 2(e). The position of the main edge in the XANES spectrum was affected by the oxidation state of the element of interest, with the initial maxima in the 1st derivative of the normalised XANES of Pd foil and PdO separated by $4 \mathrm{eV}$. It was clear that the main edge positions of all core-shell 
structured AuPd promoters were in agreement with what would be expected for metallic Pd, with no edge shifted to higher energy. The XANES spectra of a Pd foil exhibits two peaks in the 1 st derivative spectrum, due to $1 \mathrm{~s}$ to $4 \mathrm{~d}$ (these are hybridised $\mathrm{p}$ and $\mathrm{d}$ orbitals with a high degree of $\mathrm{d}$ character) and $1 \mathrm{~s}$ to $5 \mathrm{~d}$ transitions. ${ }^{35}$ For the $\mathrm{PdAu} / \mathrm{TiO}_{2}$ samples reported here the position of these peaks were shifted upon alloying, ${ }^{36}$ however, the centroid position of both features was the same for all samples (Fig. S5 in ESI $\dagger$ ). The differences in the XANES spectra beyond the main edge position between Pd foil and the coreshell structured AuPd spectra can be accounted for by the reduction of metal particle size as well as the alloying with Au. ${ }^{37}$ Unlike XPS, XANES provides a per atom average, therefore probing all environments - both surface and bulk - equally. By combining both XPS and XANES, it can be inferred that the majority of $\mathrm{Pd}$, in all samples, was presented in its metallic form, confirming the successful deposition of Pd onto the Au core.

The determined 1st shell EXAFS fitting parameters are shown in Table 3, as well as the $k^{2}$ weighted magnitude of Fourier transform data and corresponding fit shown in Fig. 3a $\left(\mathrm{Au} \mathrm{L}_{3}\right)$ and $\mathrm{b}(\mathrm{Pd} \mathrm{K})$.

The EXAFS data show that for all catalysts prepared, both the $\mathrm{Au}$ and $\mathrm{Pd}$ environments were dominated by a primary $\mathrm{Au}$ coordination shell, with similar values observed for both preparation methods. The $\mathrm{Au}-\mathrm{Au}$ and $\mathrm{Pd}-\mathrm{Au}$ coordination numbers ranged between 8.3-8.7 and 6.9-8.9, respectively, and was the most significant coordination shell in both systems. The large $\mathrm{Pd}-\mathrm{Au}$ contribution confirms that $\mathrm{Pd}$ was presented within an Au rich alloy, and not segregated as Pd overlayers. However, further addition of Pd, from the 1 ML to 2 ML systems, showed little influence on the Au EXAFS (e.g., the Au-Au coordination was not significantly altered), confirming that the majority of $\mathrm{Au}$ within the core of the particle remained unchanged. Moreover, although the Au-Pd coordination number increases

Table 3 1st shell EXAFS fitting parameters derived from the $k^{2}$ weighted Fourier transform for both $\mathrm{Au} \mathrm{L}_{3}$ and $\mathrm{Pd} \mathrm{K}$ data

\begin{tabular}{llllllll}
\hline Sample & & $\mathrm{Abs} \mathrm{Sc}$ & $N$ & $R / \AA$ & $2 \sigma^{2} / \AA^{2}$ & $E_{\mathrm{f}} / \mathrm{eV}$ & $R_{\text {factor }}$ \\
\hline $1 \mathrm{ML}(\mathrm{PD})$ & $\mathrm{Au} \mathrm{L} \mathrm{L}_{3}$ & $\mathrm{Au}-\mathrm{Au}$ & $8.7(5)$ & $2.84(1)$ & $0.008(1)$ & $4(1)$ & 0.02 \\
& & $\mathrm{Au}-\mathrm{Pd}$ & $1.5(4)$ & $2.82(3)$ & $0.009(3)$ & & \\
& $\mathrm{Pd} \mathrm{K}$ & $\mathrm{Pd}-\mathrm{O}$ & $0.3(1)$ & $1.95(1)$ & $0.001(1)$ & $1(1)$ & 0.003 \\
& & $\mathrm{Pd}-\mathrm{Pd}$ & $0.8(3)$ & $2.78(2)$ & $0.009(2)$ & & \\
& & $\mathrm{Pd}-\mathrm{Au}$ & $8.3(3)$ & $2.78(1)$ & $0.011(1)$ & & \\
$2 \mathrm{ML}(\mathrm{PD})$ & $\mathrm{Au} \mathrm{L} \mathrm{L}_{3}$ & $\mathrm{Au}-\mathrm{Au}$ & $8.3(6)$ & $2.81(1)$ & $0.008(1)$ & $4(1)$ & 0.02 \\
& & $\mathrm{Au}-\mathrm{Pd}$ & $2.2(4)$ & $2.80(2)$ & $0.009(2)$ & & \\
& $\mathrm{Pd} \mathrm{K}$ & $\mathrm{Pd}-\mathrm{O}$ & $0.3(1)$ & $1.96(1)$ & $0.001(1)$ & $1(1)$ & 0.007 \\
& & $\mathrm{Pd}-\mathrm{Pd}$ & $3.1(5)$ & $2.76(1)$ & $0.011(1)$ & & \\
& & $\mathrm{Pd}-\mathrm{Au}$ & $6.9(8)$ & $2.78(1)$ & $0.011(1)$ & & \\
$1 \mathrm{ML}(\mathrm{SR})$ & $\mathrm{Au} \mathrm{L} \mathrm{L}_{3}$ & $\mathrm{Au}-\mathrm{Au}$ & $8.4(5)$ & $2.84(1)$ & $0.008(1)$ & $4(1)$ & 0.02 \\
& & $\mathrm{Au}-\mathrm{Pd}$ & $1.7(4)$ & $2.84(2)$ & $0.010(2)$ & & \\
& $\mathrm{Pd} \mathrm{K}$ & $\mathrm{Pd}-\mathrm{Pd}$ & $0.6(2)$ & $2.75(4)$ & $0.010(4)$ & $1(1)$ & 0.006 \\
& & $\mathrm{Pd}-\mathrm{Au}$ & $8.9(3)$ & $2.78(1)$ & $0.011(1)$ & & \\
$2 \mathrm{ML}(\mathrm{SR})$ & $\mathrm{Au} \mathrm{L} \mathrm{L}_{3}$ & $\mathrm{Au}-\mathrm{Au}$ & $8.5(6)$ & $2.81(2)$ & $0.009(2)$ & $4(1)$ & 0.02 \\
& & $\mathrm{Au}-\mathrm{Pd}$ & $2.1(4)$ & $2.84(2)$ & $0.008(1)$ & & \\
& $\mathrm{Pd} \mathrm{K}$ & $\mathrm{Pd}-\mathrm{O}$ & $0.6(1)$ & $1.97(2)$ & $0.002(1)$ & $1(1)$ & 0.004 \\
& & $\mathrm{Pd}-\mathrm{Pd}$ & $1.5(2)$ & $2.76(1)$ & $0.011(2)$ & & \\
& & $\mathrm{Pd}-\mathrm{Au}$ & $7.4(3)$ & $2.78(2)$ & $0.011(1)$ & &
\end{tabular}
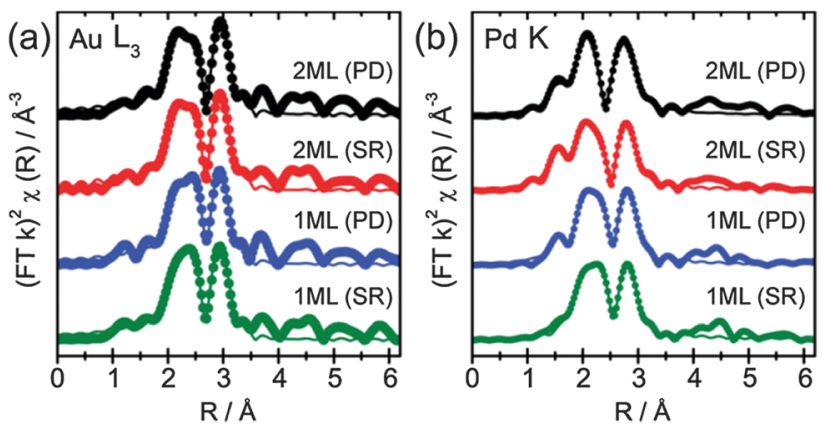

Fig. 3 (a) $A u L_{3}$ edge and (b) Pd $K$ edge for the EXAFS of the core-shell structured promoters with different thickness prepared by PD and SR methods, respectively. Dots and lines represent the magnitude of the $k^{2}$ weighted Fourier transform and associated 1st shell fittings, respectively.

with Pd loading, a much larger change would be expected if Pd was evenly distributed throughout the entirety of the particle. This can be evidenced by assessing the surface composition from XPS, which reports Au:Pd ratios of between 1:0.9 and $1: 0.4$. If one assumes these ratios broadly represent compositions of bulk structures of $\mathrm{AuPd}$ and $\mathrm{Au}_{3} \mathrm{Pd}$ random alloy, they would expect to yield 1st shell Au-Pd coordination numbers of 6 and 3, respectively. As the $\mathrm{Au}-\mathrm{Pd}$ coordination number was around 2, in all cases we can confirm that the exterior of the particle was enriched in Pd compared to the bulk. Indeed, previous work by Dimitratos et al. has demonstrated that the sequential reduction method yields particles where the Pd content remains on the exterior of the particle. ${ }^{34,38}$ Crucially, by depositing only small amounts of Pd, in conjunction with EXAFS measurements, it can be demonstrated that the outer Pd was presented within an $\mathrm{Au}$ rich alloy environment. The presence of significant quantities of Pd not associated with Au can be ruled out by the relatively low Pd-Pd coordination number, which ranges from 0.6 to 3.1. Any significant amount of Pd NPs not associated with Au would result in a much larger Pd-Pd coordination number. Moreover, a larger component of oxidic Pd would be expected for individual Pd NPs, which the XPS and XANES have shown not to be the case. The EXAFS identified a small component of Pd-O interactions, which, with the relatively low coordination numbers ( 0.3 to 0.6 ), can easily be ascribed to surface oxides as opposed to bulk PdO. An example where discrete Pd over-layers have been deposited has been demonstrated by Russell et al. ${ }^{39}$ They used controlled surface modification routes with organometallic precursors to prepare single monolayer $\mathrm{Pd}_{\text {shell }} \mathrm{Pt}_{\text {core }}$ nanoparticles on carbon. Here, cyclic voltammetry (supported by TEM-EDX line scans) was able to show surface characteristics consistent with a Pd surface. EXAFS analysis of these materials showed that the relative Pd-Pd and Pd-Pt coordination neighbours were comparable to each other, as one would expect for Pd exclusively segregated at the surface. Comparison to studies such as these provides further evidence that the Pd in these samples has been incorporated further into the NP to make an Au rich, AuPd alloy, at the surface.

As a result of the characterisation preformed on the $1 \mathrm{ML}$ and 2 ML NPs, the model of an Au core and AuPd shell structure is supported. These NPs are of the order $\sim 3 \mathrm{~nm}$ with 

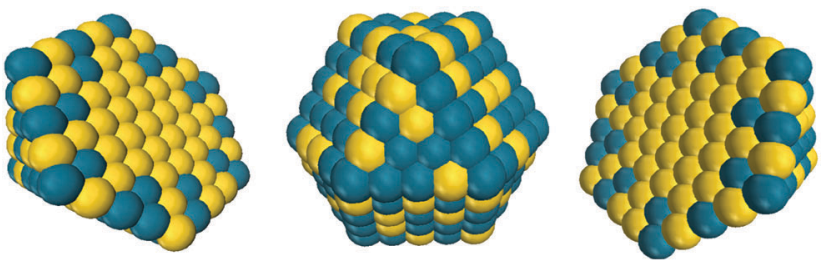

Fig. 4 Schematic diagram representing the supported model of the AuPd NPs, containing a gold core and an AuPd alloyed shell, where Au atoms are yellow and $\mathrm{Pd}$ atoms are blue. The scheme dose not quantitatively presents the composition information of the NPs.

predominant metal oxidation states of $\operatorname{Au}(0)$ and $\operatorname{Pd}(0)$. Fig. 4 represents illustrative diagrams showing the supported model of the AuPd NPs after deposition of Pd.

\section{Photocatalytic performance}

Fig. 5(a) depicts the time-resolved photocatalytic $\mathrm{H}_{2}$ evolution from 25 vol\% EtOH solution. For comparison, monometallic $\mathrm{Au}$ and $\mathrm{Pd}$ as promoters supported on $\mathrm{TiO}_{2}$ with a loading of $1 \mathrm{wt} \%$ have been prepared via sol immobilisation method and evaluated. Metal NPs decorated on $\mathrm{TiO}_{2}$ photocatalysts have shown to generate $\mathrm{H}_{2}$ under UV irradiation, however, their performance varies depending on the identity and microstructure of the promoters. Pure $\mathrm{Au}$ as the promoter showed comparable but slightly enhanced $\mathrm{H}_{2}$ production performance compared to that of pure $\mathrm{Pd}$. It was noticed that the $\mathrm{Pd} / \mathrm{TiO}_{2}$ sample showed a slight drop in photocatalytic performance compared to that of previous observations. This may arise from the difference in oxidation states of the supported Pd NPs. Whilst mainly $\mathrm{Pd}^{0}$ was observed in the current study (Fig. 2c), a mixture of $\mathrm{Pd}^{0}$ and $\mathrm{Pd}^{2+}$ exists in our previous investigations. ${ }^{18}$ Since it has been reported that the presence of noble metal oxides (PtO) supported on $\mathrm{TiO}_{2}$ can inhibit the oxidation of generated $\mathrm{H}_{2},{ }^{40}$ the drop in photocatalytic performance may be associated to the absence of PdO in this study. Interestingly, the core-shell structured $\mathrm{Pd}_{\text {shell }} \mathrm{Au}_{\text {core }}$ promoters showed further improvement in photocatalytic performance, where the $1 \mathrm{ML}$ AuPd samples yield the slightly improved performance synthesised by both photodeposition and sequential reduction methods. Evidence from XAFS characterisation indicates that the Pd is associated with the Au NPs surface, therefore the

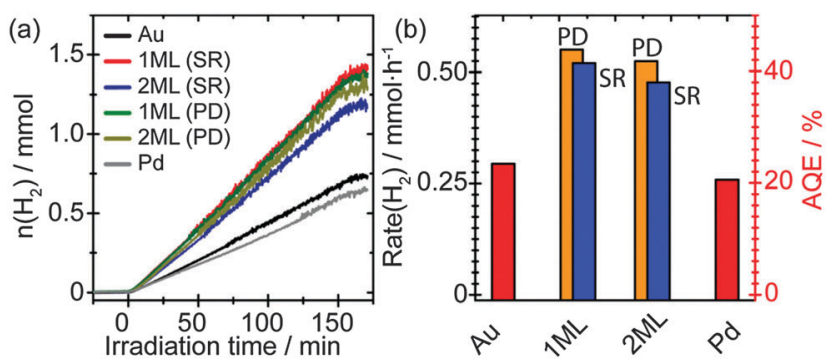

Fig. 5 (a) Photocatalytic $\mathrm{H}_{2}$ evolution from a 25 vol\% of ethanol solution using the metal/ $/ \mathrm{TiO}_{2}$ photocatalyst materials. (b) The derived $\mathrm{H}_{2}$ production rates and apparent quantum efficiencies (AQE) of the metal/ $/ \mathrm{TiO}_{2}$ photocatalyst materials. All catalysts have a metal loading of $1 \mathrm{wt} \%$. The orange and blue bars indicate the core-shell NPs prepared by photodeposition and sequential reduction methods, respectively. increase in activity can be attributed to the presence of a surface AuPd alloy at the Au NPs. Previous studies have reported that core-shell structured Au-Pd NPs demonstrate a higher activity compared to that of the random Au-Pd alloys NPs. ${ }^{18}$ It is therefore proposed that the improved activity reported here results from the interplay between the Au-core and the AuPd alloy shell of the promoter NPs. It has been reported that while Pd and Pt normally provide an ohmic contact with the semiconductor, $\mathrm{Au}$ and $\mathrm{Ag}$ normally show capacitive properties. ${ }^{17}$ Thus the AuPd alloy shell is beneficial for the rapid interfacial charge transfer of the accumulated electrons on the Au core that originated from the $\mathrm{CB}$ of $\mathrm{TiO}_{2}$. Furthermore, it was observed that the activity decreased slightly for the $2 \mathrm{ML}$ promoters compared to the $1 \mathrm{ML}$ promoters, regardless of synthesis methods, indicating the electronic properties of the promoter can be tuned precisely by engineering the thickness of surface layer. Although the total metal loading has increased after the deposition of Pd, this is not considered to be the primary reason for the increased activity. The Pd is primarily associated with the $\mathrm{Au}$ and not present as isolated Pd NPs, therefore the number of NPs would not have increased significantly. This leads to the conclusion that there has been no significant rise in the number of active sites and the increase in activity can be attributed to the structure of the NPs.

Fig. 5(b) depicts the derived $\mathrm{H}_{2}$ evolution rate and apparent quantum efficiencies (AQE) of all samples. Specifically, the $1 \mathrm{ML}$ Pd promoter on $\mathrm{TiO}_{2}$ prepared by photodeposition approach showed an impressive $\mathrm{H}_{2}$ production rate of $\sim 0.55 \mathrm{mmol} \mathrm{h}^{-1}$ that corresponding to an $\mathrm{AQE}$ of $\sim 44 \%$, which presented a twotime enhancement than that of monometallic Au promoter.

\section{Conclusions}

We demonstrate two promising approaches for the deposition of thin layers of Pd on to the surface of Au NPs using both a traditional colloidal approach and a novel photodeposition method. XPS and XAFS characterisations confirmed that the microstructures of these promoters are in the form of $\mathrm{PdAu}_{\text {shell }}{ }^{-}$ $\mathrm{Au}_{\text {core }}$, with no evidence of isolated Pd or Au NPs. The particle size of all core-shell NPs was determined to be $\sim 3 \mathrm{~nm}$ regardless of the shell thickness and preparation method. The Au and Pd were found to be predominately in their metallic form. Photocatalytic performance evaluations suggested that the $\mathrm{PdAu}_{\text {shell }}-\mathrm{Au}_{\text {core }}$ promoters exhibited improved $\mathrm{H}_{2}$ evolution compared to the monometallic ( $\mathrm{Au}$ and $\mathrm{Pd}$ ) references. The optimum reactivity was observed when $1 \mathrm{ML}$ equivalent of Pd was deposited on $\mathrm{Au}$, suggesting that a thin layer of AuPd covering an Au core can maximise the alteration in electronic properties of surface atoms therefore boost the photocatalytic hydrogen production rate. We expect by fine tuning the surface Pd composition of the Au NPs the hydrogen production performance can be further enhanced.

\section{Acknowledgements}

We acknowledge EPSRC for funding (EP/I019693/1, EP/K014714/1, and EP/I038748/1) and Diamond Light Source for provision of 
beam time (SP8071-5) and support of beamline scientists Giannantonio Cibin, Diego Gianolio, Stephen Parry and Andy Dent. The Research Complex at Harwell is also acknowledged for use of facilities and support of their staff. We also thank the financial support from the iNANO Centre through the Danish Strategic Research Council and the Carlsberg Foundation and the Centre for Materials Crystallography.

\section{Notes and references}

1 C. G. Silva, R. Juarez, T. Marino, R. Molinari and H. Garcia, J. Am. Chem. Soc., 2011, 133, 595-602.

2 M. Bowker, C. Morton, J. Kennedy, H. Bahruji, J. Greves, W. Jones, P. R. Davies, C. Brookes, P. P. Wells and N. Dimitratos, J. Catal., 2014, 310, 10-15.

3 J. M. Ogden, Annu. Rev. Energy Environ., 1999, 24, 227-279.

4 L. Saeed Al-Mazroai, M. Bowker, P. Davies, A. Dickinson, J. Greaves, D. James and L. Millard, Catal. Today, 2007, 122, 46-50.

5 H. Bahruji, M. Bowker, P. R. Davies, L. S. Al-Mazroai, A. Dickinson, J. Greaves, D. James, L. Millard and F. Pedrono, J. Photochem. Photobiol., A, 2010, 216, 115-118.

6 A. Fujishima, X. T. Zhang and D. A. Tryk, Surf. Sci. Rep., 2008, 63, 515-582.

7 K. Hashimoto, H. Irie and A. Fujishima, Jpn. J. Appl. Phys., 2005, 44, 8269-8285.

8 A. Mattsson and L. Osterlund, J. Phys. Chem. C, 2010, 114, 14121-14132.

9 M. A. Henderson, Surf. Sci. Rep., 2011, 66, 185-297.

10 M. D. Hernandez-Alonso, F. Fresno, S. Suarez and J. M. Coronado, Energy Environ. Sci., 2009, 2, 1231-1257.

11 K. M. Reddy, S. V. Manorama and A. R. Reddy, Mater. Chem. Phys., 2003, 78, 239-245.

12 J. Zhang, S. Yan, S. L. Zhao, Q. Xu and C. Li, Appl. Surf. Sci., 2013, 280, 304-311.

13 J. Greaves, L. Al-Mazroai, A. Nuhu, P. Davies and M. Bowker, Gold Bull., 2006, 39, 216-219.

14 K. Mogyorosi, A. Kmetyko, N. Czirbus, G. Vereb, P. Sipos and A. Dombi, React. Kinet. Catal. Lett., 2009, 98, 215-225.

15 Y. Z. Yang, C. H. Chang and H. Idriss, Appl. Catal., B, 2006, 67, 217-222.

16 M. S. Park and M. Kang, Mater. Lett., 2008, 62, 183-187.

17 A. Takai and P. V. Kamat, ACS Nano, 2011, 5, 7369-7376.

18 R. Su, R. Tiruvalam, A. J. Logsdail, Q. He, C. A. Downing, M. T. Jensen, N. Dimitratos, L. Kesavan, P. P. Wells, R. Bechstein, H. H. Jensen, S. Wendt, C. R. A. Catlow, C. J. Kiely, G. J. Hutchings and F. Besenbacher, ACS Nano, 2014, 8, 3490-3497.

19 V. Subramanian, E. E. Wolf and P. V. Kamat, J. Am. Chem. Soc., 2004, 126, 4943-4950.

20 Z. F. Jiang, J. J. Zhu, D. Liu, W. Wei, J. M. Xie and M. Chen, CrystEngComm, 2014, 16, 2384-2394.
21 A. Gallo, M. Marelli, R. Psaro, V. Gombac, T. Montini, P. Fornasiero, R. Pievo and V. Dal Santo, Green Chem., 2012, 14, 330-333.

22 R. Su, M. M. Forde, Q. He, Y. Shen, X. Wang, N. Dimitratos, S. Wendt, Y. Huang, B. B. Iversen, C. J. Kiely, F. Besenbacher and G. J. Hutchings, Dalton Trans., 2014, 43, 14976-14982.

23 Y. Mizukoshi, K. Sato, T. J. Konno and N. Masahashi, Appl. Catal., B, 2010, 94, 248-253.

24 R. Su, L. Kesavan, M. M. Jensen, R. Tiruvalam, Q. He, N. Dimitratos, S. Wendt, M. Glasius, C. J. Kiely, G. J. Hutchings and F. Besenbacher, Chem. Commun., 2014, 50, 12612-12614.

25 C. Brookes, P. P. Wells, G. Cibin, N. Dimitratos, W. Jones, D. J. Morgan and M. Bowker, ACS Catal., 2014, 4, 243-250.

26 N. Dimitratos, A. Villa, C. L. Bianchi, L. Prati and M. Makkee, Appl. Catal., A, 2006, 311, 185-192.

27 W. C. Ketchie, M. Murayama and R. J. Davis, J. Catal., 2007, 250, 264-273.

28 M. Newville, J. Synchrotron Radiat., 2001, 8, 322-324.

29 B. Ravel and M. Newville, J. Synchrotron Radiat., 2005, 12, 537-541.

30 R. Su, R. Tiruvalam, Q. He, N. Dimitratos, L. Kesavan, C. Hammond, J. A. Lopez-Sanchez, R. Bechstein, C. J. Kiely, G. J. Hutchings and F. Besenbacher, ACS Nano, 2012, 6, 6284-6292.

31 A. Zwijnenburg, A. Goossens, W. G. Sloof, M. W. J. Craje, A. M. van der Kraan, L. J. de Jongh, M. Makkee and J. A. Moulijn, J. Phys. Chem. B, 2002, 106, 9853-9862.

32 G. B. Hoflund, H. A. E. Hagelin, J. F. Weaver and G. N. Salaita, Appl. Surf. Sci., 2003, 205, 102-112.

33 Z. B. Wu, Z. Y. Sheng, H. Q. Wang and Y. Liu, Chemosphere, 2009, 77, 264-268.

34 N. Dimitratos, J. A. Lopez-Sanchez, J. M. Anthonykutty, G. Brett, A. F. Carley, R. C. Tiruvalam, A. A. Herzing, C. J. Kiely, D. W. Knight and G. J. Hutchings, Phys. Chem. Chem. Phys., 2009, 11, 4952-4961.

35 M. Tromp, J. A. van Bokhoven, G. P. F. van Strijdonck, P. van Leeuwen, D. C. Koningsberger and D. E. Ramaker, J. Am. Chem. Soc., 2005, 127, 777-789.

36 A. F. Lee, C. J. Baddeley, C. Hardacre, R. M. Ormerod, R. M. Lambert, G. Schmid and H. West, J. Phys. Chem., 1995, 99, 6096-6102.

37 J. W. J. Hamilton, J. A. Byrne, P. S. M. Dunlop, D. D. Dionysiou, M. Pelaez, K. O'Shea, D. Synnott and S. C. Pillai, J. Phys. Chem. C, 2014, 118, 12206-12215.

38 R. C. Tiruvalam, J. C. Pritchard, N. Dimitratos, J. A. LopezSanchez, J. K. Edwards, A. F. Carley, G. J. Hutchings and C. J. Kiely, Faraday Discuss., 2011, 152, 63-86.

39 P. P. Wells, E. M. Crabb, C. R. King, R. Wiltshire, B. Billsborrow, D. Thompsett and A. E. Russell, Phys. Chem. Chem. Phys., 2009, 11, 5773-5781.

40 Y. H. Li, J. Xing, Z. J. Chen, Z. Li, F. Tian, L. R. Zheng, H. F. Wang, P. Hu, H. J. Zhao and H. G. Yang, Nat. Commun., 2013, 4, 2500-2505. 